\title{
A multinuclear NMR study of the complexation of W(VI) with meso-2,3-dimercaptosuccinic acid (DMSA)
}

\author{
M. Madalena Caldeira, M. Luísa Ramos, Gilberto G. Pereira, Victor M.S. Gil * \\ Department of Chemistry, University of Coimbra, 3000 Coimbra, Portugal
}

Received 27 September 1999; accepted 10 November 1999

\begin{abstract}
Meso-2,3-dimercaptosuccinic acid (DMSA), which is used as an antidote for heavy metal poisoning and in complexes of ${ }^{99 \mathrm{~m}} \mathrm{Tc}$ for diagnostic purposes, forms several complexes with tungsten(VI) in aqueous solutions, as found by ${ }^{1} \mathrm{H},{ }^{13} \mathrm{C},{ }^{17} \mathrm{O}$ and ${ }^{183} \mathrm{~W}$ NMR spectroscopy. In the $\mathrm{pH}$ range $\sim 4-7$, there are four complexes in which the acid acts as a bidentate ligand through one carboxyl group and the adjacent sulfhydryl group (a dominant 2:2 species and three 1:2 metal-ligand isomers are proposed) and 2:1 complexes in which the ligand is twisted in order to use the four binding groups. It is proposed that in both the 2:2 and 2:1 cases the $\mathrm{S}$ atoms bridge the two $\mathrm{W}$ atoms. At lower $\mathrm{pH}$, the acid is again predominantly a tetradentate ligand in $m: n$ associations with the metal $(m>n)$. C 2000 Elsevier Science Ltd All rights reserved.
\end{abstract}

Keywords: meso-2,3-dimercaptosuccinic acid; Multinuclear NMR; Tunsgsten

\section{Introduction}

2,3-Dimercaptosuccinic acid (DMSA; $\mathrm{HO}_{2} \mathrm{C}-\mathrm{CHSH}$ CHSH- $\mathrm{CO}_{2} \mathrm{H}$ ), in both the meso form and as the racemic mixture, has been used in pharmacology for more than four decades, mainly as an antidote for heavy metal poisoning, particularly lead(II), in humans [1-5]; more recently, DMSA has been used as the complexing agent in the administration of technetium $\left({ }^{99 \mathrm{~m}} \mathrm{Tc}\right)$ for diagnostic purposes [69]. Several research groups have compared the antidotal actions of meso- and rac-DMSA and studied the biotransformation of the acid, in addition to more chemically oriented studies [10-12]. In particular, the ionization and the complexation equilibria have been discussed in terms of the conformations of the acids [12]. One of the advantages of the racemic mixture is the greater solubility of the complexes in water. One disadvantage is that it leads to a greater loss of endogenous zinc(II) than the meso form, because of differences in the formation constants of the complexes [13].

The complexation of DMSA with metal oxo ions has been reported in two cases: (1) oxovanadium(IV) complexes [14] in relation to the importance of V-S coordination in various biomolecules; and (2) arsenate and arsenite complexes in connection with the biotransformation of arsenic and the transfer of arsenite from glutathione to dithiols [15].

\footnotetext{
* Corresponding author. Fax: + 351-39-27703
}

In the presence of $\operatorname{As}(\mathrm{V})$, the acid is readily oxidized and the formation of a 2:3 (metal-ligand) complex with As(III) was proposed involving only the $\mathrm{SH}$ groups as donors [15]. With $\mathrm{V}(\mathrm{IV})$, the carboxyl groups are also involved in chelation [14]. As for $\operatorname{As}(V)$, the oxo ions of vanadium(V) and molybdenum(VI) are strong oxidizing agents of DMSA, but the same does not apply to tungstate. Comparison with the complexes of $\mathrm{W}(\mathrm{VI})$ with tartaric acid $[16,17]$ and with thiolactic [18] and thiomalic acids [19] leads us to expect the formation of stable complexes of DMSA with tungsten(VI). Tungsten is the active centre of some enzymes. It was only recently found that this metal can have a positive biological role, contrary to the traditional view of $\mathrm{W}$ as an antagonist of the biological functions of Mo (for a review, see [20]). In this paper we report the complexation of $\mathrm{W}(\mathrm{VI})$ with meso-2,3-dimercaptosuccinic acid in aqueous solution, at various $\mathrm{pH}$ and concentration conditions. Multinuclear magnetic resonance spectroscopy was used in one and two dimensions.

\section{Experimental}

Commercially available dihydrate sodium tungstate and meso-DMSA were used. Because of the low solubility of the acid, the metal-ligand mixtures were prepared by adding the 
appropriate amount of the solid acid to the tungstate solutions. $\mathrm{D}_{2} \mathrm{O}$ solutions were used throughout. The concentration range for the metal and the ligand was $0.025-2.0 \mathrm{M}$ and $0.10-1.0$ $\mathrm{M}$, respectively. The $\mathrm{pH}$ was adjusted by adding $\mathrm{DCl}$ and $\mathrm{NaOD}$ in $\mathrm{D}_{2} \mathrm{O}$. Drastic changes of concentration were avoided in order to reduce local disturbances of equilibria that may be slow to disappear. The $\mathrm{pH}^{*}$ values quoted (from 2.5 to 9 ) are the direct $\mathrm{pH}$-meter readings (room temperature) after standardization with aqueous $\left(\mathrm{H}_{2} \mathrm{O}\right)$ buffers.

The NMR spectra were obtained on a Varian UNITY-500 spectrometer. The residual water signal was reduced using the Presat sequence.

\section{Results and discussion}

The ${ }^{1} \mathrm{H}$ NMR spectrum due to the $\mathrm{CH}$ groups of the acid in aqueous solution is a singlet, but the doublet corresponding to the ${ }^{13} \mathrm{C}-\mathrm{H}$ satellites shows an $\mathrm{HH}$ vicinal coupling constant which varies from 10.3 to $11.4 \mathrm{~Hz}$ on increasing $\mathrm{pH}^{*}$ from 2.1 to 7.5 . This proves that, irrespective of ionization of the carboxylic groups, the meso-2,3-DMSA exists preferentially in the conformation:<smiles>O=C(O)C1CC2C(S)C1C(S)C2C(=O)O</smiles>

In this conformation, the repulsion between the bulky sulfhydryl groups is minimized. Essentially the same result is found for methanol-water mixtures as a solvent of lower dielectric constant.

In the presence of sodium tungstate, and depending on the molar ratio and on $\mathrm{pH}$, a large number of signals (at higher frequency relative to free ligand) is observed corresponding to bound ligand. Except at low $\mathrm{pH}$ and in the presence of excess of metal ion, free ligand is also present, in slow exchange (in the NMR time scale) with the bound ligands. Apart from one set of broad signals close to the residual water (DHO) signal, each bound ligand gives rise to two comparatively sharp doublets of equal intensity (AX spectrum) instead of singlets. The vicinal HH coupling constant is now directly obtained. A set ( six AX spectra) dominant at moderate $\mathrm{pH}(\sim 4-7)$ and for metal-ligand molar ratios equal or below to 1 (group A complexes) shows couplings between 7.5 and $9.2 \mathrm{~Hz}$ and proton shifts that vary from 0.3 to 0.6 ppm for one of the doublets and from 0.9 to $1.2 \mathrm{ppm}$ for the other, as illustrated in Fig. 1 and tabulated in Table 1. In the same $\mathrm{pH}$ range but for metal-ligand molar ratios greater than 1, a set of four to six broad singlets are recorded at 1.2-1.4 ppm to high frequency of free ligand (group B complexes).

At low $\mathrm{pH}(\sim 3)$ and for metal-ligand ratios greater than 1, a set of five well-resolved AX spectra of about the same intensity are recorded, showing splittings that lie between 3.0 and $3.8 \mathrm{~Hz}$ and high-frequency shifts relative to free ligand

f.lig.

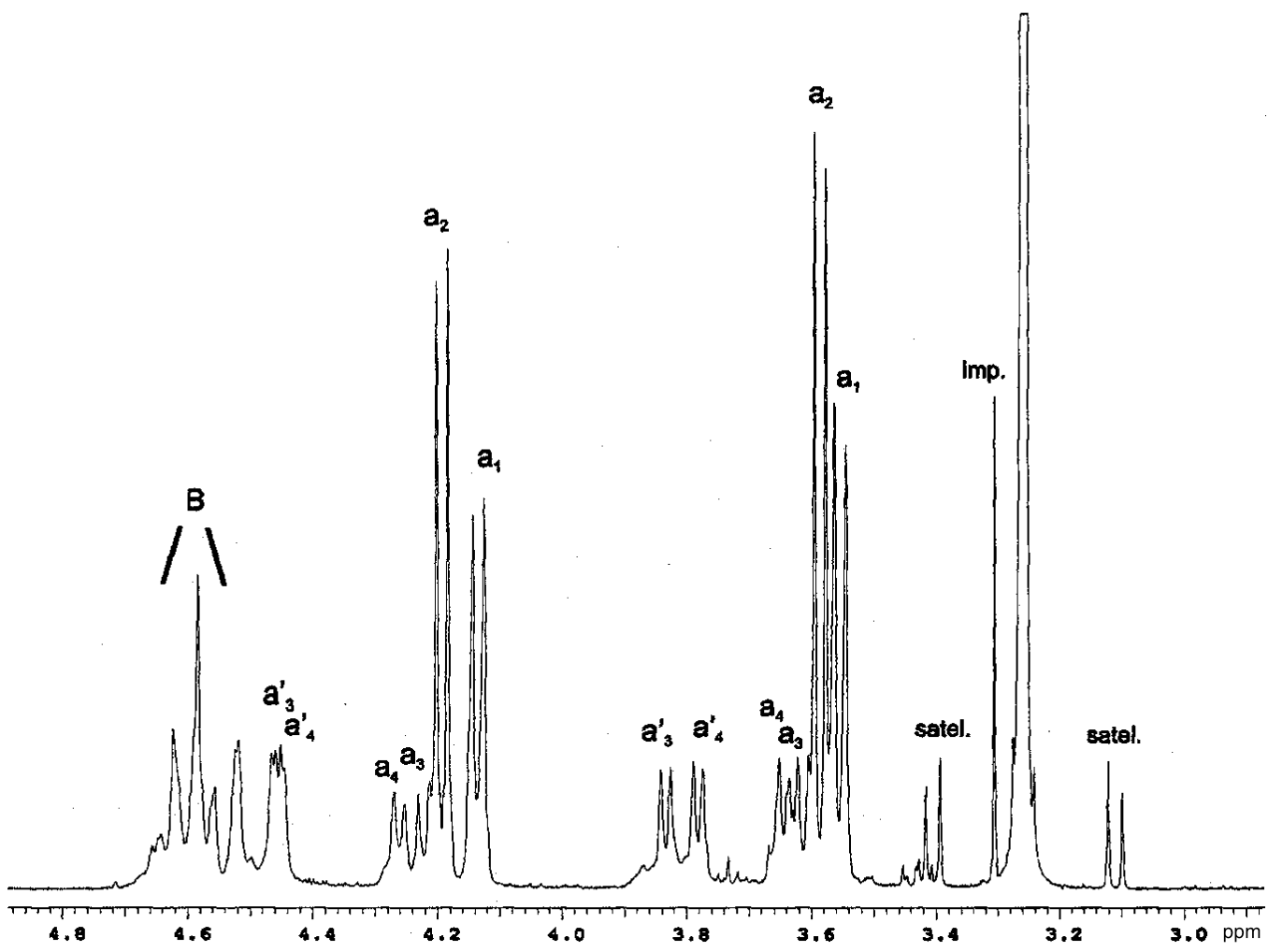

Fig. 1. $500 \mathrm{MHz}{ }^{1} \mathrm{H}$ NMR spectrum of a $0.10 \mathrm{M}: 0.40 \mathrm{M}$ solution of sodium tungstate and meso-DMSA in $\mathrm{D}_{2} \mathrm{O}$, pH* 5.4, $298 \mathrm{~K}$. f. lig. denotes free ligand; imp. denotes ligand impurity; satel. denotes satellite. 
Table 1

${ }^{1} \mathrm{H}$ NMR parameters ${ }^{\text {a }}$ for $\mathrm{W}(\mathrm{VI})+$ meso-DMSA (at $298 \mathrm{~K}$ )

\section{pH 5.4}

Free ligand

B

$\mathrm{a}_{1}$
$\mathrm{a}_{2}$
$\mathrm{a}_{3}$
$\mathrm{a}_{3}^{\prime}$
$\mathrm{a}_{4}$
$\mathrm{a}_{4}^{\prime}$

$\mathrm{a}_{3}{ }_{3}$

pH 2.9

Free ligand

$\mathrm{C}_{1}$

$\mathrm{C}_{2}$

$\mathrm{C}_{3}$

$\mathrm{C}_{4}$

$\mathrm{C}_{5}$ $\delta=3.26$

$\delta=4.5-4.7$

$\delta_{\mathrm{A}}$

3.55

3.59

3.61

3.83

3.64

3.78

$\delta=3.40$

\begin{tabular}{l}
$\delta_{\mathrm{A}}$ \\
\hline 4.4 \\
4.4 \\
4.42 \\
4.39 \\
4.37
\end{tabular}

\begin{tabular}{|c|c|}
\hline$\Delta \delta_{\mathrm{A}}$ & $\delta_{x}$ \\
\hline 0.29 & 4.13 \\
\hline 0.33 & 4.19 \\
\hline 0.35 & 4.22 \\
\hline 0.57 & 4.46 \\
\hline 0.38 & 4.26 \\
\hline 0.52 & 4.45 \\
\hline
\end{tabular}

\begin{tabular}{l}
$\Delta \delta_{\mathrm{A}}$ \\
\hline 1.0 \\
1.0 \\
1.02 \\
0.99
\end{tabular}

0.97

\begin{tabular}{l}
$\delta_{x}$ \\
\hline 4.92 \\
4.93 \\
4.95 \\
4.99 \\
5.02
\end{tabular}

$\Delta \delta_{x}$

$\begin{array}{ll}0.88 & 9.2 \\ 0.93 & 8.9 \\ 0.96 & 8.9 \\ 1.20 & 7.5 \\ 1.00 & 8.2 \\ 1.19 & 7.2\end{array}$

${ }^{3} J_{\mathrm{HH}}=11.2$

${ }^{3} J_{\mathrm{HH}}=10.5$

\begin{tabular}{r}
$\Delta \delta_{x}$ \\
\hline 1.51 \\
1.52 \\
1.55 \\
1.58 \\
1.61
\end{tabular}

${ }^{3} J_{\mathrm{HH}}$

3.2

3.8

3.2

3.0

${ }^{\mathrm{a}} \delta$ values are in ppm relative to $\mathrm{Me}_{4} \mathrm{Si}$, using tert-butyl alcohol $\left(\delta_{\mathrm{H}}=1.2\right)$ as internal reference; $J$ values are in $\mathrm{Hz}$.

HDO

imp.

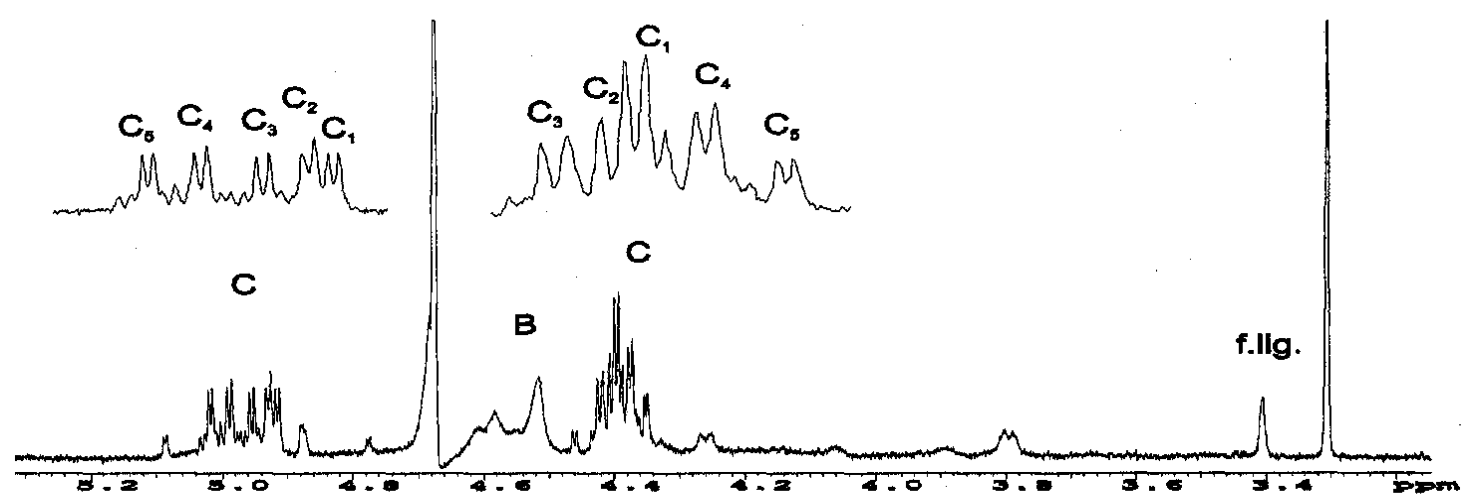

Fig. 2. $500 \mathrm{MHz}{ }^{1} \mathrm{H}$ NMR spectrum of a $0.40 \mathrm{M}: 0.10 \mathrm{M}$ solution of sodium tungstate and meso-DMSA in $\mathrm{D}_{2} \mathrm{O}$, pH* 2.9, $298 \mathrm{~K}$. f. lig. denotes free ligand; imp. denotes ligand impurity.

of about 1.0 and $1.6 \mathrm{ppm}$ (group C complexes) (Fig. 2 and Table 1). Some weaker signals are also detected in the latter case. The assignment of each pair of doublets in each AX spectrum was made on the basis of the coupling constants and, in the case of doubt, by proton decoupling and COSY spectra.

The number of complexes is likely to be smaller than the number of spectra of bound ligand, as magnetic non-equivalence of ligands may occur in complexes having more than one ligand molecule. For example, the AX spectra $\mathrm{a}_{3}$ and $\mathrm{a}_{3}{ }^{\prime}$ in Fig. 1 always have the same intensity irrespective of $\mathrm{pH}$ and concentration conditions, and the same is found for $\mathrm{a}_{4}$ and $\mathrm{a}_{4}{ }^{\prime}$. This suggests that each of these pairs of AX spectra arise from the same complex, probably having 1:2 (metalligand) stoichiometry. Accordingly, there will be four complexes in group A. When a Job's plot is constructed based on the ${ }^{1} \mathrm{H}$ NMR intensities for complexes $\mathrm{A}$, at $\mathrm{pH}^{*}$ 5.5, a clear maximum at $1: 1$ is obtained for the dominant complex, $A_{1}$, which points to an n:n stoichiometry. Due to the presence of various competing species, no other firm conclusion can be directly extracted from that plot alone, but 1:2 complexes are likely to be formed by analogy with thiolactic [18] and thiomalic acids [19] and tartaric acid [16,17].

The existence of one small high-frequency proton shift (0.3-0.6 ppm) upon complexation together with a higher one (0.9-1.2 ppm) indicate the involvement of only one sulfhydryl group in complexes A, whereas the observation of high-frequency shifts (1.0-1.6 ppm) for both $\mathrm{CH}$ protons in complexes $\mathrm{B}$ and $\mathrm{C}$ show that both $\mathrm{S}$ atoms are bound to the metal. This is corroborated by the corresponding ${ }^{13} \mathrm{C}$ shifts relative to free ligand in the same conditions. In fact, for complex A (at $\mathrm{pH}^{*} 5.5$ ), high-frequency complexation shifts between 4.0 and $5.0 \mathrm{ppm}$ are observed for the ${ }^{13} \mathrm{C}$ bonded to the more deshielded $\mathrm{H}$ atom, and almost no shift for the other. For complexes B and $\mathrm{C}$, the two ${ }^{13} \mathrm{C}(\mathrm{SH})$ complexation shifts (at $\mathrm{pH}^{*} 2.8$ ) lie in the range $7-8 \mathrm{ppm}$. Whenever necessary, 
the assignment of the ${ }^{13} \mathrm{C}$ signals was made by running HETCOR 2D spectra.

Complexes A also involve only one of the carboxylate groups in bonding to the metal, as shown by a high-frequency shift on complexation (in the range 5-7 ppm) of one of the $\mathrm{CO}_{2}{ }^{-}$groups, together with a low-frequency shift of about $-0.8 \mathrm{ppm}$ for the other group. On the other hand, both carboxylate ${ }^{13} \mathrm{C}$ signals of complexes $\mathrm{B}$ and $\mathrm{C}$ shift between 7 and 8 ppm to high frequency, which shows that both carboxylate groups now participate in complexation.

Based on the above data, we can propose that the acid acts as a bidentate ligand in complexes A, involving one carboxylic group and the adjacent $\mathrm{SH}$ group, irrespective of the stoichiometry being $\mathrm{n}: \mathrm{n}$ or 1:2. The conformation of DMSA is slightly changed on complexation, as indicated by $\mathrm{HH}$ couplings of 7.5-9.2 Hz in the complexes compared with 10$11 \mathrm{~Hz}$ in the free ligand. Since a 1:1 complex, involving two water molecules bound to the metal, is not expected to be particularly stable, we propose a 2:2 species with the following structure, in which the ligand molecules are magnetically equivalent:

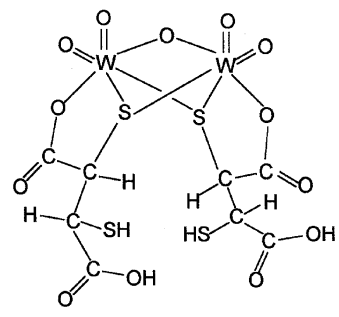

Regarding complexes having 1:2 stoichiometry, we note that several diastereoisomers are possible, for example:

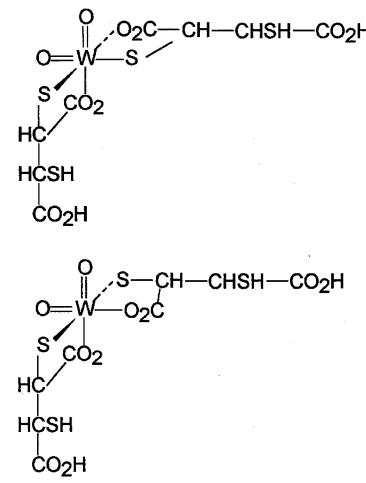

In complexes $\mathrm{B}$ and $\mathrm{C}$, the ligand acts as tetradentate and undergoes much alteration of conformation on binding to the metal. In fact, the $\mathrm{HH}$ coupling constants recorded for complexes $\mathrm{C}$ lie between 3.0 and $3.8 \mathrm{~Hz}$, showing that the conformation of bound DMSA is now close to:<smiles>O=C(O)C1CC2C(S)CC1C(S)C2C(=O)O</smiles>

The same conclusion must apply to complexes B, as the line width of each signal is about $3 \mathrm{~Hz}$. In spite of this con- formational change, a molecular model suggests that it is highly unlikely that a tetradentate DMSA molecule is bound to just one $\mathrm{W}$ atom. The same has been recently advanced in the case of complexes of DMSA with tin [21]. The formation of several polynuclear species must then occur. This is corroborated by the fact that complexes B are dominant for high metal-ligand molar ratios. One of the possible structures is

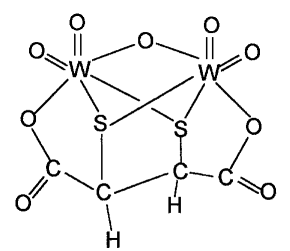

which is similar to that previously found by X-ray diffraction for a 2:1 complex of Mo(VI) with L-dithiothreitol [22].

Broad ${ }^{1} \mathrm{H}$ NMR signals are a result of complexes B having close proton resonances (a range of $0.2 \mathrm{ppm}$ ) that no longer correspond to first-order spectra.

The proposal of similar metal centres, $\mathrm{W}_{2} \mathrm{O}_{5}{ }^{2+}$, for the most abundant complexes $\mathrm{A}$ and $\mathrm{B}$ (2:2 and 2:1 species, respectively), which are present in a 1.0:1.0 $\mathrm{M} \mathrm{W(VI)-}$ meso-DMSA solution in $\mathrm{D}_{2} \mathrm{O}$, at $\mathrm{pH}^{*} 7.0$, is corroborated by the occurrence of ${ }^{183} \mathrm{~W}$ resonances between +579 and +592 ppm with respect to an external reference of $\mathrm{Na}_{2} \mathrm{WO}_{4}$ in $\mathrm{D}_{2} \mathrm{O}$ $\left(\mathrm{pH}^{*}\right.$ 9.5), besides the three signals due to uncomplexed $\mathrm{W}_{7} \mathrm{O}_{24}{ }^{6-}$ (at $+269,-92$ and $\left.-179 \mathrm{ppm}\right)[23,24]$. Values close to $+600 \mathrm{ppm}$ were also recorded for the systems $\mathrm{W}(\mathrm{VI})$-thiolactic acid and W(VI)-thiomalic acid. The ${ }^{17} \mathrm{O}$ spectra of the same solution shows the signals of $\mathrm{W}_{7} \mathrm{O}_{24}{ }^{6-}$ (terminal and bridging $\mathrm{O}$ atoms) [23,24] and some new signals: a major peak at +534.5 ppm (relative to $\mathrm{D}_{2} \mathrm{O}$ as external reference) which lies in the region of $\mathrm{W}=\mathrm{O}$ resonances [25] and a smaller one at $+270.8 \mathrm{ppm}$ in the region of $\mathrm{W}-\mathrm{O}-\mathrm{W}$ signals [25]. This also points to the presence of a $\mathrm{W}_{2} \mathrm{O}_{5}{ }^{2+}$ moiety in the $2: 2$ and $2: 1$ complexes.

For a 2.0:0.5 M solution at $\mathrm{pH}^{*} 4.3$, where complexes B dominate, we have again several ${ }^{183} \mathrm{~W}$ signals between +580 and $+593 \mathrm{ppm}$ (besides those of $\mathrm{W}_{7} \mathrm{O}_{24}{ }^{6-}$ ). An additional and sharp signal appears at $-120 \mathrm{ppm}$, the resonance of the $\alpha$-metatungstate ion, $\alpha-\mathrm{H}_{2} \mathrm{~W}_{12} \mathrm{O}_{40}{ }^{6-}$ [23]. A similar signal has been detected in solutions of tungstate and mandelic or isocitric acids and attributed to 2:2 complexes involving two oxygen bridges [17]. We prefer to attribute the above resonance to the isopolyanion expected to be present at low $\mathrm{pH}$, but additional studies are necessary.

Regarding signals $\mathrm{C}$, dominant for high metal-ligand molar ratios and low $\mathrm{pH}$, which are the conditions for polytungstate anions to be present in significant concentrations, we again propose an $\mathrm{m}: \mathrm{n}$ complexation, with $\mathrm{m}>\mathrm{n}$. The fact that there are five AX spectra in this set, all with approximately the same intensity, suggests that a major polynuclear complex $\mathrm{C}$ is present involving five ligands in slightly different magnetic conditions. However, further studies are needed to clarify this and other points of such a complicated 
system. We therefore plan to go back to our previous work on simpler systems $[18,19]$ and carefully run ${ }^{17} \mathrm{O}$ and ${ }^{183} \mathrm{~W}$ NMR spectra.

\section{Acknowledgements}

This work has been supported by a grant from the Fundação para a Ciência e Tecnologia (Praxis Qui-63/96) of the Portuguese Ministry of Science and Technology.

\section{References}

[1] Y. Liang, C. Chu, Y. Tsen, K. Ting, Acta Physiol. Sin. 21 (1957) 24.

[2] H.V. Aposhian, Annu. Rev. Pharmacol. Toxicol. 23 (1983) 193.

[3] D.C. Jones, G.L. Smith, P.M. May, D.R. Williams, Inorg. Chim. Acta 93 (1984) 93.

[4] M. Rivera, H.V. Aposhian, Q. Fernando, J. Inorg. Biochem. 37 (1989) 283.

[5] H.V. Aposhian, R.M. Maiorino, D. Gonzalez-Ramirez, M. ZumigaCharles, Z. Xu, K.M. Hurlbut, P. Junko-Munoz, R.C. Dart, M.M. Aposhian, Toxicology 97 (1995) 23.

[6] T.H. Lin, A. Khentigan, H.S. Winchell, J. Nucl. Med. 15 (1974) 34.

[7] I. Ikeda, I. Osamu, K. Kurata, J. Nucl. Med. 18 (1977) 1222.
[8] H. Ohta, K. Yamamoto, K. Endo, T. Mori, D. Hamanaka, A. Shimazu, K. Ikekubo, K. Makimoto, Y. Iida, J. Konishi, R. Morita, N. Hata, K. Horiuchi, A. Yokoyama, K. Torizuka, K. Kuma, J. Nucl. Med. 25 (1984) 323.

[9] K. Horinchi, S. Hiedo, A. Yokoyama, Nucl. Med. Biol. 25 (1998) 689.

[10] X. Fang, Q. Fernando, Chem. Res. Toxicol. 7 (1994) 148.

[11] X. Fang, Q. Fernando, Chem. Res. Toxicol. 7 (1994) 882.

[12] X. Fang, Q. Fernando, Chem. Res. Toxicol. 8 (1995) 525.

[13] X. Fang, Q. Fernando, Chem. Res. Toxicol. 7 (1994) 770

[14] T. Kiss, P. Buglyó, G. Micera, A. Dessi, D. Sanna, J. Chem. Soc., Dalton Trans. (1993) 1849.

[15] M. Delnomdedieu, M.M. Basti, J.D. Otvos, D.J. Thomas, Chem. Res. Toxicology 6 (1993) 598.

[16] A.M. Cavaleiro, J.D. Pedrosa de Jesus, R.D. Gillard, P.A. Williams, Transition Met. Chem. 9 (1984) 81.

[17] M. Hlaibi, S. Chapelle, M. Benaissa, J.-F. Verchère, Inorg. Chem. 34 (1995) 4434.

[18] M.M. Caldeira, V.M.S. Gil, Polyhedron 5 (1986) 381.

[19] M.M. Caldeira, V.M.S. Gil, Can. J. Chem. 62 (1984) 2094.

[20] M.K. Johnson, D.C. Rees, M.W.W. Adams, Chem. Rev. (1996) 2817.

[21] K. Gajda-Schrantz, L. Nagy, E. Kuzmann, A. Vértes, J. Holecek, A Lycka, J. Chem. Soc., Dalton Trans. (1997) 2201.

[22] S.J.N. Burgmayer, E.I. Stiefel, Inorg. Chem. 27 (1988) 2518.

[23] J.J. Hastings, O.W. Howarth, J. Chem. Soc., Dalton Trans. (1992) 209.

[24] R.I. Maksimovskaya, K.G. Burtseva, Polyhedron 4 (1985) 1559.

[25] M.L. Ramos, M.M.Caldeira, V.M.S. Gil, Carbohydr. Res. 299 (1997) 209. 